\title{
Pharmacoepidemiology of ascites and associated complications in hospitalized patients: descriptive observational study
}

\author{
*Hirra Tasneem, Huda Shahbaz and Bushra Ali Sherazi \\ Institute of Pharmacy, Lahore College For Women University, Jail Road Lahore, 54000, Pakistan
}

\begin{abstract}
Ascites is the pathological accumulation of free fluid in peritoneal cavity. The aim of the present study was to observe the prevalence, clinical management and the assessment of complications associated with ascites in hospitalized patients. A Descriptive Observational Study was conducted at two tertiary care hospitals of Lahore. The data was collected on a data collection form containing questions regarding basic patient information, presenting symptoms, clinical management and associated complications. Verbal informed consent was taken and confidentiality was maintained. Pilot study was performed prior to performance of a fullscale research project. The results are expressed in the form of frequency and percentages. A total of fifty (50) ascitic patients were evaluated during two months. It was slightly more common in females $(58 \%)$ as compared to males $(42 \%)$. Common causes of Ascites were Liver Cirrhosis (80\%), Chronic Renal Failure (10\%), Peritoneal Malignancy and Peritoneal Tuberculosis (4\%) each and Cardiac Failure (2\%). The mainstay for the first line treatment in patients with cirrhosis includes education regarding dietary sodium restriction and oral diuretics. The major complications associated with Ascites were Protein malnutrition (87\%), Mental Confusion (73\%), Hepatorenal Syndrome (21\%) and Spontaneous Bacterial Perotinitis (8\%). In most patients ascites was being managed successfully by limiting the salt intake and provision of a diuretic regimen. As, ascites is a starting point for more serious complications; so, its early diagnosis should be ensured. Social media and NGOs should play their role in creating the awareness regarding this deadly disease.
\end{abstract}

Key Words: Ascites, prevalence, SAAG, transudative, exudative, cirrhosis, spironolactone.

\section{INTRODUCTION}

Ascites is a deadly disease, which is also common in Pakistan. Ascites is the most common complication of cirrhosis and is related with a poor quality of health, high risks of infections, renal failure and a poor long-term outcome (Anderson, 2002). Hepatitis C and alcoholism are the most common causes of Cirrhosis and they also contributed to death in Unites States as $12^{\text {th }}$ leading cause in 2000, holding responsibility for more than 25,000 deaths (Moore and Wong, 2003). If noticed for 10 years, almost $60 \%$ of cirrhotic patients develop ascites needing therapy (Karin et al., 2013). Existence of ascites is related with 60$70 \%$ five-year mortality rate (Patel, 2014).

The effect and uses of drugs studied in a welldefined population is referred to as Pharmacoepidemiology (Strom and Brian, 2006). Ascites is derived from a Greek term "ASKOS" which refers to a bag or sac. It is the pathological accumulation of free fluid in the peritoneal cavity. The fluid accumulates because of conditions directly involving the peritoneum (infection, malignancy), or due to other diseases remote from the peritoneum (i.e., liver disease, heart failure, hypoproteinaemia) (Muhammed et al., 2012; Al Knawy, 1997).

Serum Ascitic Albumin Gradient (SAAG) was found to be the parameter for the distribution of ascitic fluid into Transudative and Exudative type. Transudative Fluid or High Gradient Ascitic Fluid was referred to as the fluid having SAAG $>1.1 \mathrm{~g} / \mathrm{dl}$, while on the other hand SAAG $<1.1 \mathrm{~g} / \mathrm{dl}$ was referred to as Exudative Fluid or Low Gradient Ascitic Fluid (Shaikh et al., 2010).

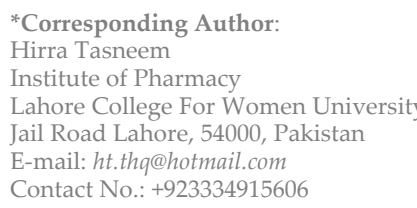

Cirrhosis is the commonest cause of ascites in the Western world $(75 \%)$, followed by peritoneal malignancy $(12 \%)$, cardiac failure $(5 \%)$ and peritoneal tuberculosis (2\%) (Runyon, 1993).

The major co-morbid of ascitic patients are fever, abdominal pain, night sweats, weight loss, abdominal swelling, and clubbing and palmer erythema (Qureshi et al., 2001). The most prevalent symptoms are increased abdominal girth and recent weight gain. The expeditious onset of symptoms in a matter of weeks in ascites helps to distinguish it from obesity, which develops over a period of months to years (Simel et al., 1988).

Ascites is normally treated while an underlying cause is known, to avoid complications, relieve symptoms, and prevent further progression. An outpatient therapy is usually given for the patients suffering from mild Ascites. The major aim of the therapy for both the patients with peripheral edema and ascites is the weight loss, which should not be more than $1.5 \mathrm{~kg} /$ day and should not be more than $0.5 \mathrm{~kg} /$ day for ascitic patients alone. In severe ascites when patient complains about tense abdomen, then paracentesis is usually performed after hospitalizing the patient (Ginès et al., 1987).

The initial treatments in High SAAG are Salt restriction, which allows diuresis (production of urine) as the patient now has more fluid than salt concentration. Salt restriction is successful in about $15 \%$ of patients (Gatta et al., 1991).

As salt restriction is the basic concept in the treatment, and aldosterone is one of the hormones that act to increase salt retention, so a medication that counteracts aldosterone should be given. So, the drug of choice is spironolactone, as the aldosterone receptors are blocked by it in collecting tubule. Other distal-tubule diuretics e.g. amiloride or triamterene can also be used. This choice has been affirmed in a randomized controlled trial. Dose of diuretics for ascites should be once daily (Fogel et al., 1981). 
In patients with severe (tense) ascites, therapeutic paracentesis may be desirable. As paracentesis may decline the levels of serum albumin in the blood, so, albumin may need to be given intravenously in fraction to the quantity of ascites removed (Salerno et al., 1987).

In patients with ascites possible associated complications are spontaneous bacterial peritonitis, hepatorenal syndrome, weight loss and protein malnutrition, mental confusion, change in the level of alertness, or coma and other complications related to liver cirrhosis (Mehta and Rothstein, 2009).

Our research study investigates that what were the main causes, clinical symptomatology and complications of Ascites in Pakistan especially in Lahore; it also investigates the prevalence of Ascites and the major clinical finding of ascitic patients. The main reason for finding out the major causes, complications of Ascites and clinical findings that were associated with it was that they could be managed more effectively and given proper treatment accordingly.

\section{MATERIALS AND METHODS}

\section{Study Type}

A Descriptive observational study was conducted at Medicine wards of Chronic Kidney Disease and Chronic Liver Disease in Sir Ganga Raam Hospital and Services Hospital Lahore, Pakistan. The duration of study was 2 months (July 2014 - August 2014) and 50 hospitalized patients of Ascites in medicine wards of Chronic Kidney Disease and Chronic Liver Disease were selected as subjects for this study.

\section{Methodology}

A data collection form was designed to collect the information from the admitted patients in the medicine wards of Chronic Kidney Disease and Chronic Liver Disease with the diagnosis of Ascites. Data collection form covered the different aspects regarding patient's demographic information, past medical history, family history, medication history, diagnosis and management, results of abdominal examination, presenting complaints, causes of Ascites, associated complications and result of laboratory analysis report. Verbal informed consent was taken and confidentiality was maintained. Pilot study was performed first, in order to find any problem in data collection and to improve upon the study design prior to performance of a full-scale research project. Collected data was recorded in data collection form. The descriptive statistics was applied using Microsoft Excel® and the frequency and percentages were calculated and results were expressed in tables and figures.

\section{RESULTS AND DISCUSSION}

Ascites is one of the serious clinical problems of Pakistan. A total of fifty ascitic patients were evaluated, which indicated that females are more prone as compared to males. As showed in table 1 , it was $42 \%$ in males and $58 \%$ in females; our results were comparable to a local study conducted in Karachi (Muhammed et al., 2012).

Among the causes of ascites chronic liver disease happened to be the most prominent cause i.e. $80 \%$ of cirrhotic patients advance to ascites, $10 \%$ of renal failure, $2 \%$ cardiac failure, $4 \%$ peritoneal malignancy and $4 \%$ tuberculosis lead to ascites (table 1). Literature showed that Cirrhosis is the commonest cause of ascites in the Western world ( 75\%) (Runyon, 1993). The presence of ascites leads to the progression of cirrhosis. It is also the most common cause for hospital admissions and thus increases unpredicted cost; it increases 1-year mortality and functions as a risk for orthotopic liver transplantation (OLT). Cirrhotic ascites, in the setting of portal hypertension, comprises approximately $85 \%$ of all cases. Other causes of ascites (non-cirrhotic) can be broadly defined as pre- or post-hepatic in origin (Moore and Thiel, 2013).

In our study the most common type of fluid found in the peritoneal cavity was of transudative type $(86 \%)$, and its main cause was found to be Liver Cirrhosis as depicted in table 1 and table 2 . While the prominent cause for the exudative type of fluid was found to be chronic renal failure. These results were almost same as found in other local and Middle East study (Muhammed et al., 2012; Al Knawy, 1997).

Traditionally, ascites was divided into 2 types, Transudative and Exudative type. This classification was based on the amount of protein found in the fluid. A more meaningful system has been developed, which is based on the amount of albumin in the ascitic fluid compared to the serum albumin (albumin measured in the blood). This system is called the Serum Ascites Albumin Gradient or SAAG. SAAG value is usually $>1.1 \mathrm{~g} / \mathrm{dl}$ in Ascites due to portal hypertension (Budd-Chiari syndrome, congestive heart failure, cirrhosis). While the value $<1.1 \mathrm{~g} / \mathrm{dl}$ indicates that Ascites is due to other causes e.g. pancreatitis or malignancies (Shaikh et al., 2010). Our study reveals that a low gradient of SAAG $(<1.1 \mathrm{~g} / \mathrm{dL})$ was not due to increased portal pressure but its causes were tuberculosis, pancreatitis, nephrotic syndrome and various types of peritoneal cancer. While, a high gradient of SAAG $(>1.1 \mathrm{~g} / \mathrm{dL})$ showed that ascites was associated with Liver Cirrhosis, Congestive Cardiac Failure and Chronic Renal Failure as shown in table 2.

Table 1: Prevalence, laboratory findings and causes of ascites.

\begin{tabular}{clcc}
\hline & Variables & $\begin{array}{c}\text { Frequency } \\
\text { (n=50) }\end{array}$ & Percentage \\
\hline \multirow{2}{*}{ Sex } & Males & 21 & $42 \%$ \\
& Females & 29 & $58 \%$ \\
\hline Laboratory & Exudative fluid & 7 & $14 \%$ \\
Findings & Transudative fluid & 43 & $86 \%$ \\
\hline \multirow{5}{*}{ Causes } & Chronic liver disease & 40 & $80 \%$ \\
& (Cirrhosis) & 5 & $10 \%$ \\
& Chronic Renal Failure & 2 & $4 \%$ \\
& Peritoneal Malignancy & 1 & $2 \%$ \\
& Cardiac Failure & 2 & $4 \%$ \\
& Peritoneal Tuberculosis & - & - \\
\hline
\end{tabular}

Table 2: Causes of high SAAG \& low SAAG ascites.

\begin{tabular}{|c|c|c|c|}
\hline \multicolumn{2}{|r|}{ Variables } & \multirow[t]{2}{*}{$\mathbf{n}$} & \multirow[t]{2}{*}{$\%$} \\
\hline \multirow{9}{*}{$\begin{array}{l}\text { Causes of high } \\
\text { SAAG or } \\
\text { transudative } \\
\text { type of fluid }\end{array}$} & Liver Cirrhosis & & \\
\hline & Hepatitis C & 32 & $74.4 \%$ \\
\hline & Hepatitis $B$ & 5 & $11.6 \%$ \\
\hline & Hepatic Encephalopathy & 2 & $4.6 \%$ \\
\hline & Alcohol & - & - \\
\hline & Hepatocellular Carcinoma & 1 & $2.3 \%$ \\
\hline & Congestive Cardiac Failure & 1 & $2.3 \%$ \\
\hline & Chronic Renal Failure & 2 & $4.6 \%$ \\
\hline & Budd Chiari Syndrome & - & - \\
\hline \multirow{4}{*}{$\begin{array}{c}\text { Causes of low } \\
\text { SAAG or } \\
\text { exudative type } \\
\text { of fluid }\end{array}$} & $\begin{array}{l}\text { Malignancy (primary peritoneal } \\
\text { carcinomatosis and metastasis) }\end{array}$ & 2 & $28.5 \%$ \\
\hline & Chronic Renal Failure & 3 & $42.8 \%$ \\
\hline & Tuberculosis & 2 & $28.5 \%$ \\
\hline & Pancreatitis & - & - \\
\hline
\end{tabular}




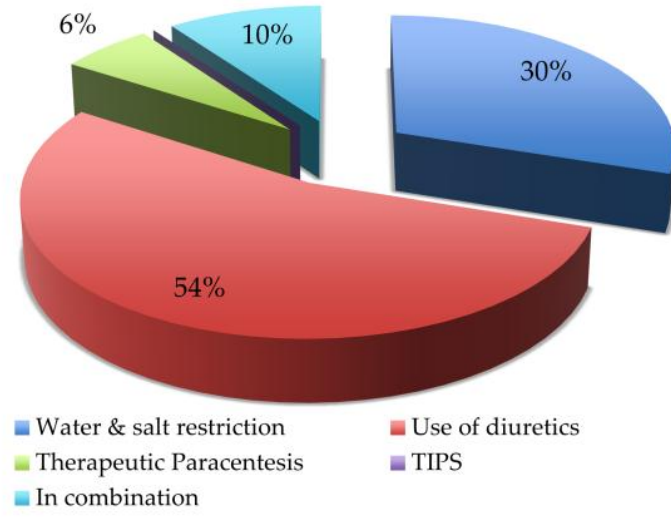

Figure 1: Current approach for the treatment of ascites.

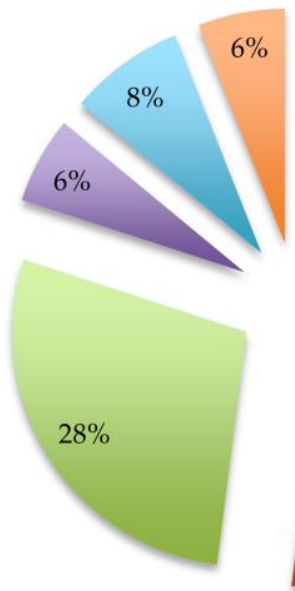

Spironolactone

Spironolactone+Furosemide

플 Hydrochlorothiazide

Figure 2: Frequency of usage of diuretics for ascites management

The initial treatment in high SAAG ("transudate") is salt restriction, which allows diuresis (production of urine) as the patient now has more fluid than salt concentration. Salt restriction is successful in about $15 \%$ of patients (Gatta et al., 1991). Among diuretics Spironolactone is the drug of choice as they block the aldosterone receptor in the collecting tubule. This choice has been affirmed in a randomized controlled trial (Fogel et al., 1981). Our study reveals that most patients $(54 \%)$ were using diuretics for the management of Ascites and 30\% of them were following the water and salt restriction as shown in figure 1 . Among diuretics spironolactone (34\%) and combination of spironolactone and furosemide (28\%) were being prominently used as highlighted in figure 2 .

The most prevalent symptoms are recent weight gain and increased abdominal circumference. As fluid continues to amass, diaphragm elevates and shortness of breath occurs. Fluid aggregation may also be related with a feeling of satiety and generalized abdominal pain. The
Table 3: Presenting symptoms, co-morbid conditions \& complications associated with ascites.

\begin{tabular}{clcc}
\hline & \multicolumn{1}{c}{ Variables } & n & \% \\
\hline \multirow{3}{*}{ Presenting } & Weight gain & 36 & $72 \%$ \\
Symptoms & Dyspnea & 43 & $86 \%$ \\
& Abdominal Swelling & 44 & $88 \%$ \\
& Sense of fullness \& bloating & 45 & $90 \%$ \\
& Changes to the navel (belly button) & 43 & $86 \%$ \\
& Ankle swelling & 13 & $26 \%$ \\
\hline \multirow{3}{*}{ Co-morbid } & Fever & 19 & $38 \%$ \\
Conditions & Abdominal Pain & 24 & $48 \%$ \\
& Weight Loss & 20 & $40 \%$ \\
& Palmer Erythema & 19 & $38 \%$ \\
& Clubbing & 26 & $52 \%$ \\
\hline \multirow{5}{*}{ Complica- } & Spontaneous Bacterial Peritonitis & 4 & $8 \%$ \\
tions & Hepatorenal Syndrome & 14 & $28 \%$ \\
& Protein Malnutrition & 43 & $86 \%$ \\
& Mental Confusion & 36 & $72 \%$ \\
& Change in level of Alertness & 32 & $64 \%$ \\
& Coma (Hepatic Encephalopathy) & 3 & $6 \%$ \\
\hline
\end{tabular}

expeditious onset of symptoms in a matter of weeks in ascites helps to distinguish it from obesity, which develops over a period of months to years (Simel et al., 1988). According to our study majority of the patients complained about sense of fullness and bloating, dyspnea, weight gain and abdominal swelling.

It was found in our study that major co-morbid conditions with ascites were clubbing, abdominal pain, and weight loss, fever and palmer erythema. These results were comparable to various Turkish, South African and local studies that divulge the same major co-morbid of ascitic patients (Manohar et al., 1990; Shaikh et al., 2010; Vardareli et al., 2004).

In patients with ascites possible associated complications are spontaneous bacterial peritonitis (a lifethreatening infection of the ascites fluid), hepatorenal syndrome (kidney failure), protein malnutrition and weight loss, change in the level of alertness, mental confusion, or hepatic encephalopathy (coma) and other complications related to liver cirrhosis (Mehta and Rothstein, 2009). In our study the most common associated complications were found to be protein malnutrition, mental confusion and changes in the level of alertness. While few patients also suffered from hepatorenal svndrome and spontaneous bacterial perotinitis. Frequency of presenting symptoms, co-morbid conditions and complications associated with ascites are shown in table 3 .

Ascites is not fatal unless it becomes infected. Infection often causes the hepatorenal syndrome leading to death. Prophylaxis with antibiotic was seen for secondary prevention of spontaneous bacterial peritonitis and in high- risk patients.

Although, this research was an important study on the topic of Ascites but still there was room for enhancement, which need further study on this topic. First of all, the study was restrained only to two hospitals. Although this study was conducted in government sector hospitals which draws people who belongs to a lower class and lower-middle class of our society and depicts a true picture of ascites in Pakistan as majority of population comes under this group, it still would have been more effective if this study was carried out in private hospitals as well, where majority of the upper class with better socioeconomic condition visits. 


\section{CONCLUSION}

Ascites is a lethal disease, which is also common in Pakistan. Its most common cause is found to be Liver Cirrhosis. Salt restriction and use of diuretics are recommended for its effective management. If left untreated, this can lead to severe complications. So, early diagnosis and effective treatment should be ensured. Social Media and NGO's should play their role in providing awareness to people regarding this fatal disease.

\section{ACKNOWLEDGEMENT}

We would like to show our sincere regards to Prof. Dr. Maqsood Ahmad, Director of Institute of Pharmacy, Lahore College For Women University, Lahore, and all the supervisors who helped us in conducting this study. Even our thanks would not be enough for their tremendous support and help, without their encouragement and guidance this study would not have materialized.

\section{REFERENCES}

Al Knawy, B.A. (1997). Etiology of Ascites and the diagnostic value of serum-ascites albumin gradient in non-alcohol liver disease. Annals of Saudi Medicine, Volume 17, Issue 1, Pages 26-28.

Anderson, R.N. Hyattsville, National Center for Health Statistics. Deaths: leading causes for 2000. National vital statistics reports 2002, Volume 50, Issue 16. [DOI]

Fogel, M.R., Sawhney, V.K, Neal, E.A., Miller, R.G., Knauer, C.M. and Gregory, P.B. (1981). Diuresis in the ascetic patient: a randomized controlled trial of three regimens. Journal of Clinical Gastroenterology, Volume 3, Suppl 1, Pages 73-80. [DOI]

Gatta, A., Angeli, P., Caregaro, L., Menon, F., Sacerdoti, D and Merkel, C. (1991). A pathophysiological interpretation of unresponsiveness to spironolactone in a stepped-care approach to the diuretic treatment of ascites in nonazotemic cirrhotic patients. Hepatology Volume 14, Issue 2, Pages 231-236. [DOI]

Ginès, P., Arroyo, V., Quintero, E., Planas, R., Bory, F., Cabrera, J., Rimola, A., Viver, J., Camps, J., Jiminéz, W., Mastai, R., Gaya, J and Rodés, J. (1987). Comparison of paracentesis and diuretics in the treatment of cirrhotics with tense ascites. Results of a randomized study. Gastroenterology, Volume 93, Issue 2, Pages 234-241. [DOI]

Karin, B., Cesario, Choure, A., William, D and Carey. (2013) Cirrhotic Ascites, The Cleveland Clinic Foundation, Center for Continuing Education, Euclid Avenue, KK31, Cleveland, OH 44195

Manohar, A., Simjee, A.E., Haffejee, A.A. and Pettengell, K.E. (1990). Symptoms and investigative findings in 145 patients with tuberculous peritonitis diagnosed by peritoneoscopy and biopsy over a five-year period. Gut, Volume 31, Pages 1130-1132. [DOI]

Mehta, G. and Rothstein, K.D. (2009). Health maintenance issues in cirrhosis. Medical Clinics of North America, Volume 93, Pages 901-915. [DOI]

Moore, C.M. and Thiel, D.H. (2013). Cirrhotic ascites review: Pathophysiology, diagnosis and management. World Journal of Hepatology, Volume 5, Issue 5, Pages 251-263. [DOI]

Moore, K.P and Wong F. (2003). The management of ascites in cirrhosis: report on the consensus conference of the International Ascites Club. Hepatology, Volume 38, Pages 258-66. [DOI]

Muhammed, H., Aslam, Saleem, S., Alvi, A.A. and Hasan, S.S. (2012). Epidemiology and Symptomatology of Exudative and Transudative type of Ascites in Hospitalized Patients. Pakistan Journal of Pharmacology, Volume 29, Issue 2, Pages 1-6.

Patel, P. Just In Time medicine. Michigan State University. 2014 Jan [Accessed: July, 2014]. Available from: [Link]

Qureshi, A., Jamshaid, Siddiqui, M. and Zafar, S.A. (2001). Clinical spectrum of Cirrhosis of liver due to HCV in Jinnah Hospital. Pakistan Postgraduate Medical Journal, Volume 12, Issue 3, Pages: 104-107.

Runyon, B.A. (1993) Ascites, In: Schiff L, Schiff ER, eds. Diseases of the Liver. (Volume 2, pp. 990 - 1015). Philadelphia: Lippincott Company. [DOI]

Salerno, F., Badalamenti, S., Incerti, P., Tempini, S., Restelli, B., Bruno, S. Bellati, G. and Roffi, L. (1987). Repeated paracentesis and i.v. albumin infusion to treat 'tense' ascites in cirrhotic patients. A safe alternative therapy. Journal of Hepatology, Volume 5, Issue 1, Pages 102-108. [DOI

Shaikh, M.A., Khan, J., Almani, S., Dur-e-Yakta and Shaikh, D. (2010). Frequency of causes of ascites in patients admitted at medical unit of a tertiary medical care facility. Journal of Ayub Medical College, Abottabad, Volume 22, Issue 2, Pages 88-92.

Simel, D.L., Halvorsen R.A. Jr. and Feussner, J.R. (1988). Quantitating bedside diagnosis: clinical evaluation of ascites. Journal of General Internal Medicine, Volume 3, Pages 423 - 428. [DOI]

Strom and Brian. (2003) Textbook of Pharmacoepidemiology. (pp.3). West Sussex, England: John Wiley and Sons. [DOI]

Vardareli, E., Kebapci, M., Saricam, T., Pasaoglu, O. and Açikalin, M. (2004). Tuberculous peritonitis of the wet ascetic type: Clinical feature and diagnostic value of image-guided peritoneal biopsy. Digestive and Liver Disease, Volume 36, Issue 3, Pages 199-204. [DOI] 